\title{
Cloning and characterization of the Type I Baeyer-Villiger monooxygenase from Leptospira biflexa
}

\author{
Romina D. Ceccoli ${ }^{1}$, Dario A. Bianchi ${ }^{2}$, Michael J. Fink ${ }^{3,4}$, Marko D. Mihovilovic ${ }^{3}$ and Daniela V. Rial ${ }^{*}$
}

\begin{abstract}
Baeyer-Villiger monooxygenases are recognized by their ability and high selectivity as oxidative biocatalysts for the generation of esters or lactones using ketones as starting materials. These enzymes represent valuable tools for biooxidative syntheses since they can catalyze reactions that otherwise involve strong oxidative reagents. In this work, we present a novel enzyme, the Type I Baeyer-Villiger monooxygenase from Leptospira biflexa. This protein is phylogenetically distant from other well-characterized BVMOs. In order to study this new enzyme, we cloned its gene, expressed it in Escherichia coli and characterized the substrate scope of the Baeyer-Villiger monooxygenase from L. biflexa as a whole-cell biocatalyst. For this purpose, we performed the screening of a collection of ketones with variable structures and sizes, namely acyclic ketones, aromatic ketones, cyclic ketones, and fused ketones. As a result, we observed that this biocatalyst readily oxidized linear- and branched- medium-chain ketones, alkyl levulinates and linear ketones with aromatic substituents with excellent regioselectivity. In addition, this enzyme catalyzed the oxidation of 2-substituted cycloketone derivatives but showed an unusual selection against substituents in positions 3 or 4 of the ring.
\end{abstract}

Keywords: Baeyer-Villiger monooxygenase, Biocatalysis, Leptospira, Ketones

\section{Introduction}

Baeyer-Villiger monooxygenases (BVMOs) comprise a rapidly growing group of enzymes recognized by their ability as oxidative biocatalysts. They are known to catalyze the oxidation of ketones to esters or lactones mainly, although other oxidation reactions have also been described for these enzymes such as epoxidations on carbon-carbon double bonds, sulfoxidations, and oxidations of boron and selenium compounds. The BVMOs are classified as Type I, Type II and atypical BVMOs. Type I BVMOs contain non-covalently bound flavin adenine dinucleotide (FAD) as coenzyme and strictly depend on reduced nicotinamide adenine dinucleotide phosphate (NADPH) as source of reducing power. They are the best studied BVMOs and the ones proven in scale-up biotransformation assays, as reviewed in (Balke et al. 2012;

\footnotetext{
*Correspondence: rial@inv.rosario-conicet.gov.ar; drial@fbioyf.unr.edu.ar 1 Área Biología Molecular, Departamento de Ciencias Biológicas, Facultad de Ciencias Bioquímicas y Farmacéuticas, Universidad Nacional de Rosario, CONICET, Suipacha 531, S2002LRK Rosario, Argentina Full list of author information is available at the end of the article
}

Bučko et al. 2016; Ceccoli et al. 2014; de Gonzalo et al. 2010; Leisch et al. 2011). Discovery and analysis of new BVMOs have been favored by intensive cloning strategies and high throughput methods that facilitated the expansion of the number of recombinantly available Type I BVMOs in the last decade (Torres Pazmiño et al. 2010). Several examples exist regarding the practical use of BVMOs as whole-cell biocatalysts in organic synthesis. Mihovilovic et al. (2006) reported the formal total synthesis of showdomycin, trans-kumausyne and goniofufurone analogs by chemoenzymatic approaches that included a key BVMO-mediated ketone oxidation to an intermediate chiral lactone. Few years later and by using a similar approach, Bianchi et al. (2013) reported the synthesis of $(+)$ and $(-)$ non-natural carba- $C$-nucleosides by accessing antipodal intermediate lactones in very good yields and high enantiomeric excess (ee). Recently, further applications of these antipodal lactones obtained by biooxidation mediated by two different BVMOs were reported (Rudroff et al. 2016). Moreover, BVMOs are also capable for combination within chemo-enzymatic 
transformations employing heterogeneous catalysis (Fink et al. 2013) as well as construction of artificial metabolic mini-pathways in vivo (Oberleitner et al. 2013) and in vitro (Oberleitner et al. 2014). Recently, demonstrations of prospective technological applications were presented: (1) BVMOs were utilized for the production of hydroxypropionic acid derivatives for bio-based bulk-chemical supply (Fink and Mihovilovic 2015), (2) an enzyme cascade allowed the synthesis of oligo- $\varepsilon$ caprolactone at more than $20 \mathrm{~g} / \mathrm{L}$ when starting from $200 \mathrm{mM}$ cyclohexanol by the sequential action of an alcohol dehydrogenase, a BVMO, and a subsequent direct ring-opening oligomerization of the $\varepsilon$-caprolactone formed using lipase A from Candida antarctica (Schmidt et al. 2015) and, (3) an in vivo biocatalytic cascade demonstrated the valorization of orange peel waste as starting material towards chiral carvolactone by a direct multi-step conversion that involved an oxygenation reaction catalyzed by a BVMO (Oberleitner et al. 2017).

Leptospira biflexa is a free-living bacterium of the genus Leptospira, order Spirochaetales, present in aquatic and soil environments. The genome of this saprophytic species had been sequenced in 2008 (Picardeau et al. 2008). As part of a bioinformatic survey for BVMOs sequences we decided to investigate the presence of genes coding for putative Type I BVMOs in the genome of $L$. biflexa. In this work, we describe the cloning of the gene coding for the Type I BVMO from L. biflexa, its expression in Escherichia coli and a complete characterization of this new BVMO $\left(\mathrm{BVMO}_{\text {Lepto }}\right)$ as a whole-cell biocatalyst. The results are discussed and compared with data available in the literature for other Baeyer-Villiger biooxidations.

\section{Materials and methods}

\section{Sequence alignment and phylogenetic analysis}

Protein sequences of BVMOs (Additional file 1: Table S1) were aligned with MAFFT (Multiple Alignment using Fast Fourier Transform) version 7 (Katoh and Standley 2013). Phylogenetic trees were generated using the LG substitution model in PhyML 3.0 (Guindon et al. 2010). Branch support was calculated using the approximate likelihood ratio test (aLRT) with a ShimodairaHasegawa-like (SH-like) procedure. Phylogenetic trees were visualized using FigTree v1.3.1 (Rambaut and Drummond 2010).

\section{General}

Chemical reagents as well as reagents for Molecular Biology were from commercial sources (Promega Corp., Madison, WI, USA; Invitrogen Corp., Carlsbad, CA, USA; Sigma-Aldrich Corp., St. Louis, MO, USA; Merck KGaA, Darmstadt, Germany; Genbiotech S.R.L., CABA,
Argentina; BD (Becton, Dickinson and Company), Franklin Lakes, NJ, USA; Cicarelli Laboratorios, San Lorenzo, Argentina; Bio Basic Inc., Markham, ON, Canada; MP Biomedicals, Santa Ana, CA, USA). Substrates used in this study were either commercial or synthesized in our laboratories. Solvents were distilled before use.

\section{Plasmid construction, microbial strains and culture media} A DNA fragment containing the selected BVMO gene from L. biflexa (CP000786.1, Protein ABZ97795.1; previously YP_001839071.1) was obtained by polymerase chain reaction (PCR) of genomic DNA using primers 5'-GATTCGCTAGCATGACAACATCAGGTTTTAG- $3^{\prime}$ and $5^{\prime}$-ACTGCCTCGAGTTATTGGGTGGTGAGAC- $3^{\prime}$ that contain NheI and $X h o I$ recognition sites, respectively. The PCR amplification was performed with $P f u$ DNA polymerase (Promega Corp, Madison, WI, USA) according to the manufacturer protocol and supplemented with $5 \%(\mathrm{v} / \mathrm{v})$ dimethyl sulfoxide. The amplified DNA fragment corresponding to the predicted length (1489 base pairs) was digested and ligated into compatible sites of pET-TEV plasmid (Houben et al. 2007) to produce the pHLb01 plasmid. All DNA purifications were carried out using the Wizard ${ }^{\circledR}$ SV Gel and PCR Clean-Up System (Promega Corp, Madison, WI, USA). The recombinant plasmid was isolated using Wizard ${ }^{\circledR}$ Plus SV Miniprep DNA Purification System (Promega Corp, Madison, WI, USA) and its sequence was confirmed by DNA sequencing. E. coli strains were chemically transformed with the plasmid by standard procedures (Sambrook et al. 1989), and grown at $37{ }^{\circ} \mathrm{C}$ in LB-agar medium $(5 \mathrm{~g} / \mathrm{L}$ yeast extract, $10 \mathrm{~g} / \mathrm{L}$ peptone, and $5 \mathrm{~g} / \mathrm{L} \mathrm{NaCl}, 15 \mathrm{~g} / \mathrm{L}$ agar) supplemented with $50 \mu \mathrm{g} / \mathrm{mL}$ kanamycin.

The genomic DNA from L. biflexa serovar Patoc strain Patoc 1 (Paris) was kindly provided by Prof. Eduardo A. Ceccarelli from Instituto de Biología Molecular y Celular de Rosario, Rosario, Argentina and Prof. Mathieu Picardeau from Institut Pasteur, Paris, France (Picardeau et al. 2008). The strain L. biflexa serovar Patoc strain Patoc1 (Paris) (CRBIP6.1176) is maintained in the Centre de Ressources Biologiques de l'Institut Pasteur, Paris, France.

\section{Protein expression}

A pre-culture of E. coli BL21(DE3) cells transformed with pHLb01 plasmid was grown overnight in LB medium supplemented with $50 \mu \mathrm{g} / \mathrm{mL}$ kanamycin. Then, fresh LB medium with kanamycin was inoculated with the overnight pre-culture $[2 \%(\mathrm{v} / \mathrm{v})]$ and incubated at $37^{\circ} \mathrm{C}$ until optical density $\mathrm{OD}_{600}=0.4-0.6$ was reached. Next, isopropyl $\beta$-D-1-thiogalactopyranoside (IPTG) was added to induce recombinant gene expression at $0.3 \mathrm{mM}$ final concentration and the culture was transferred to $24^{\circ} \mathrm{C}$. In 
order to analyze flavoprotein production, the cells were harvested by centrifugation after overnight induction and resuspended in $50 \mathrm{mM}$ Tris- $\mathrm{HCl}$ buffer, $\mathrm{pH} 8$ containing $150 \mathrm{mM} \mathrm{NaCl}, 0.05 \mathrm{mg} / \mathrm{mL}$ lysozyme, $0.1 \mathrm{mM}$ benzamidine and $0.5 \%(\mathrm{v} / \mathrm{v})$ triton $\mathrm{X}-100$. The cell homogenate was centrifuged at $4{ }^{\circ} \mathrm{C}$ for $15 \mathrm{~min}$ at $12,000 g$. The presence of $\mathrm{BVMO}_{\text {Lepto }}$ in the soluble and insoluble fractions was analyzed by SDS-PAGE on 12\% polyacrylamide gel.

\section{Whole-cell biotransformations}

Biotransformations of linear- and branched-chain ketones as well as some aromatic and cyclic ketones were carried out in $10 \mathrm{~mL}$ cultures. Recombinant gene expression was induced at $0.3 \mathrm{mM}$ IPTG and substrates were added as solutions prepared in ethanol $(0.5$ or $0.1 \mathrm{mg} / \mathrm{mL}$ final concentration, as required). After $24 \mathrm{~h}$ of reaction at $24{ }^{\circ} \mathrm{C}$, analytical samples were centrifuged and the supernatant $(0.7 \mathrm{~mL})$ was extracted with diethyl ether $(0.7 \mathrm{~mL})$ supplemented with $0.5 \mathrm{mg} / \mathrm{mL}$ 1,3,5-trimethylbenzene as internal standard. The organic phase was removed, dried with anhydrous $\mathrm{Na}_{2} \mathrm{SO}_{4}$, and analyzed by gas chromatography-mass spectrometry (GC-MS; Shimadzu GCMSQP2010 Plus from Shimadzu Corporation, Kyoto, Japan) using an achiral and/or a chiral capillary column (SPB-1 Capillary GC Column or $\beta$-DEX 325, respectively, $30 \mathrm{~m} \times 0.25 \mathrm{~mm}$ ID, $0.25 \mu \mathrm{m}$ film, from Supelco, Bellefonte, PA, USA). Reaction products were predicted by GC-MS or by comparison with reference biotransformations, when possible. Other ketones including levulinic esters and most of cyclic ketones were assayed using 24-well plates following the general procedure described in (Rial et al. 2008a, b) with minor modifications. In this case, $\beta$-cyclodextrin $(4.0 \mathrm{mM})$ was supplemented as a cell membrane transfer agent; the culture was thoroughly shaken and then divided into $1.0 \mathrm{~mL}$ aliquots. Substrates were added as solutions in 1,4-dioxane $(4.0 \mathrm{mM}$ final concentration), the plates were sealed with adhesive film and incubated at $24{ }^{\circ} \mathrm{C}$ for $24 \mathrm{~h}$. After centrifugal separation of the cell mass, samples were prepared by extraction of the biotransformation culture $(0.5 \mathrm{~mL})$ with ethyl acetate $(1.0 \mathrm{~mL})$ containing $1.0 \mathrm{mM}$ methyl benzoate as internal standard and analyzed by chiral-phase GC-FID (Thermo Scientific Trace or Focus, Thermo Fisher Scientific, Waltham, MA, USA) using columns BGB175 or BGB173 (30 m $\times 0.25 \mathrm{~mm}$ ID, $0.25 \mu \mathrm{m}$ film) from BGB Analytik AG (Boeckten Switzerland) or achiral-phase GC-FID (Thermo Scientific Trace or Focus) using column TR5-MS ( $15 \mathrm{~m} \times 0.25 \mathrm{mM}$ ID, $0.10 \mu \mathrm{m}$ film) from Thermo Fisher Scientific, Waltham, MA, USA. All biotransformations were performed as triplicates; conversion and selectivity are reported. Whenever possible, optical rotation signs of products were assigned on the basis of published reference biotransformations.

\section{Results}

\section{Protein sequence analysis}

We investigated the presence of BVMOs in L. biflexa by bioinformatic approaches and detected only one sequence corresponding to a putative Type I BVMO. In order to study this protein sequence, phylogenetic relationships were established amongst recombinantly available BVMOs both from eukaryotes and prokaryotes (Fig. 1; Additional file 1: Table S1). The topology of the un-rooted tree (Fig. 1a) showed different clades of Type I BVMO sequences corresponding to the previously defined groups I to VII (Ferroni et al. 2014; Szolkowy et al. 2009). The $\mathrm{BVMO}_{\text {Lepto }}$ shares $29-33 \%$ sequence identity with proteins of the group IV that includes BVMOs with an N-terminal extension such as BVMO18 from Rhodococcus jostii RHA1 (30\% sequence identity) and HAPMO from Pseudomonas putida JD1 (33\% sequence identity) (Additional file 1: Table S1). The sequence of the putative $\mathrm{BVMO}_{\text {Lepto }}$ clusters with several divergent Type I BVMOs with variable and/or partially characterized substrate scope and shares approximately $34-44 \%$ sequence identity with BVMOs in this clade. Recombinant expression of several BVMOs belonging to this cluster was negligible or its activity was not detected: BVMO6, BVMO7 and BVMO17 from $R$ jostii (Riebel et al. 2012; Szolkowy et al. 2009), and BVMO1 from Mycobacterium tuberculosis H37Rv (Bonsor et al. 2006) (Fig. 1a). According to our analysis, the $\mathrm{BVMO}_{\text {Lepto }}$ groups in a subclade together with the BVMO1 from M. tuberculosis H37Rv (Fig. 1a) and they share $44 \%$ sequence identity (Additional file 1: Table S1). Taking all this into account, the $\mathrm{BVMO}_{\text {Lepto }}$ is an interesting candidate to be functionally produced in $E$. coli and characterized as a biocatalyst in order to contribute to the knowledge of Type I BVMOs.

The two Rossmann-fold motifs for dinucleotide-binding (GxGxxG/A) and the characteristic Type I BVMO consensus sequences (G/AGxWxxxxF/YPG/MxxxD and FxGxxxHxxxWP/D) are conserved in the new $\mathrm{BVMO}_{\text {Lepto }}$, as it is shown in a multiple sequence alignment of $\mathrm{BVMO}_{\text {Lepto }}$ and representative Type I BVMOs from different clades (Fig. 1b; Additional file 1: Figure S1): 4-hydroxyacetophenone monooxygenase (HAPMO) from Pseudomonas fluorescens ACB (32\% sequence identity, group IV), cyclohexanone monooxygenase (CHMO) from Acinetobacter sp. NCIMB 9871 (30\% sequence identity, group III), phenylacetonone monooxygenase (PAMO) from Thermobifida fusca (27\% sequence identity, group II), cyclododecanone monooxygenase (CDMO) from Rhodococcus ruber SC1 (28\% sequence identity, group VII) and cyclopentanone monooxygenase (CPMO) from Comamonas sp. NCIMB 9872 (27\% sequence identity, group I). The $\mathrm{BVMO}_{\text {Lepto }}$ consists of 488 amino acids and it is characterized by the lack of 52 


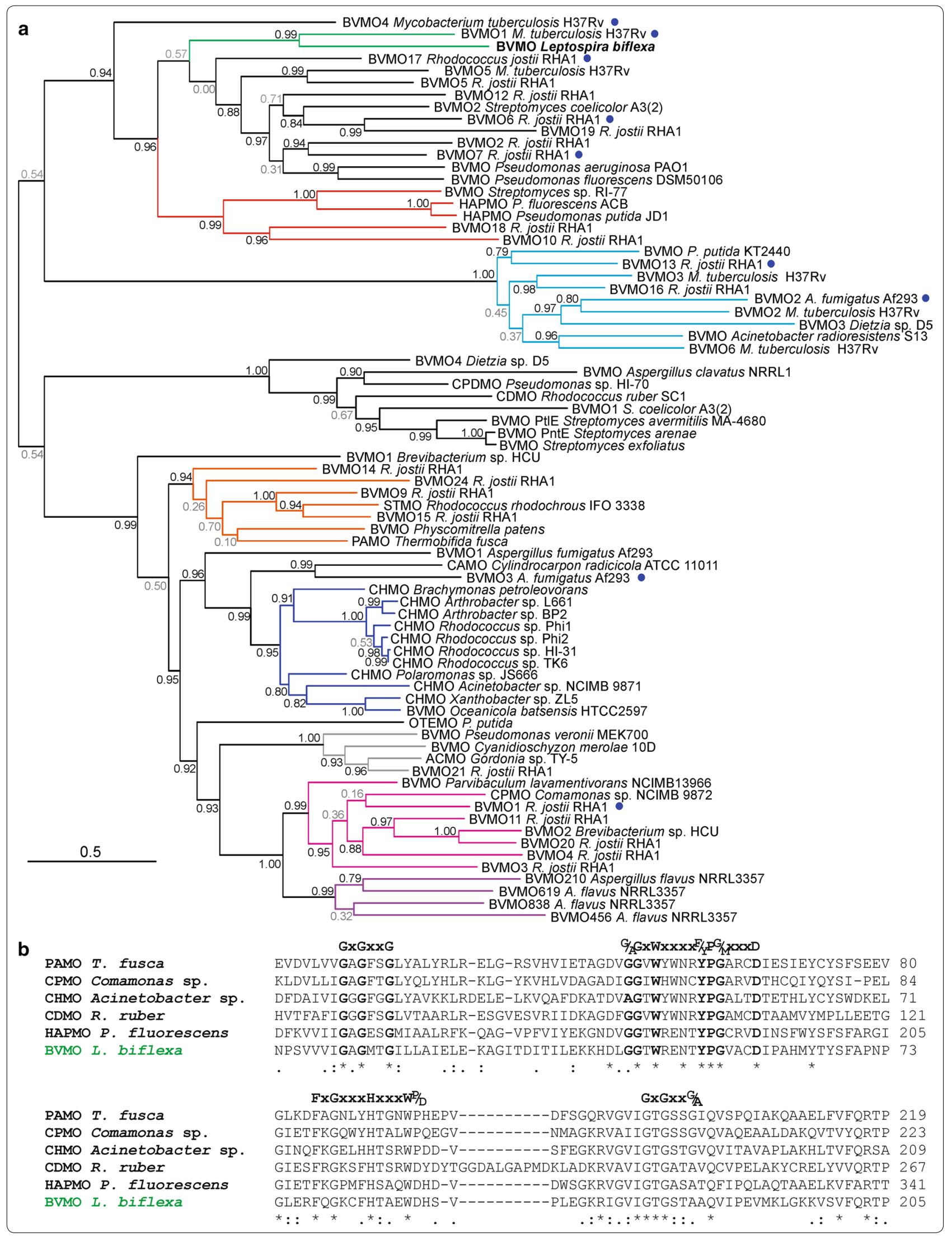


(See figure on previous page.)

Fig. 1 Sequence homology analysis of $\mathrm{BVMO}_{\text {Lepto }}$ a Maximum-likelihood phylogenetic tree of recombinant BVMOs. The scale bars indicate the number of substitutions per site per unit of branch length. The aLRT values are shown at the nodes: $>0.75$ (black) and $<0.75$ (grey). The colors of branches indicate the groups I (pink), II (orange), III (blue), IV (red), V (cyan), VI (violet) and VII (gray) as previously defined (Ferroni et al. 2014; Szolkowy et al. 2009). Blue circles indicate recombinant BVMOs that were insoluble or their activity was not detected. BVMO from L. biflexa is indicated in bold. Protein sequences with their corresponding accession numbers are listed in Additional file 1: Table S1. b Multiple sequence alignment of six representative BVMOs belonging to different clades. The partial alignment of PAMO from T. fusca (Q47PU3), CHMO from Acinetobacter sp. NCIMB 9871 (BAA86293), HAPMO from P. fluorescens ACB (AAK54073), CPMO from Comamonas sp. NCIMB 9872 (BAC22652), CDMO from R. ruber SC1 (AAL14233) and BVMO from L. biflexa (ABZ97795) is shown. The two Rossmann-fold motifs (GxGxxG/A) and the two consensus sequences of Type I BVMOs (G/ AGxWxxxxF/YPG/MxxxD and FxGxxxHxxxWP/D) are written in bold

residues that comprise one helical turn (positions 257259), one helix (positions 262-276) and a second short helix (positions 278-284) in the polypeptide chain of the CHMO from Rhodococcus sp. HI-31 (Additional file 1: Figure S2).

\section{Cloning and expression of $\mathrm{BVMO}_{\text {Lepto }}$ in E. coli}

The gene coding for $\mathrm{BVMO}_{\text {Lepto }}$ was amplified by PCR from genomic DNA and cloned into the pET-TEV vector as it is described in "Materials and methods". Upon induction of gene expression, the full-length $\mathrm{BVMO}_{\text {Lepto }}$ was produced as fusion to an N-terminal His-Tag (expected size $54 \mathrm{kDa}$ ). The presence of $\mathrm{BVMO}_{\text {Lepto }}$ in protein extracts of induced $E$. coli cells was analyzed by SDS-PAGE and Coomassie Blue staining (Fig. 2). A major band of estimated $54 \mathrm{kDa}$ that matched with the expected size of the recombinant $\mathrm{BVMO}_{\text {Lepto }}$ was detected both in the soluble and insoluble fractions of the induced culture. Approximately $60 \%$ of the protein was obtained in soluble form (Fig. 2, lanes 1 and 2). This band was not detected

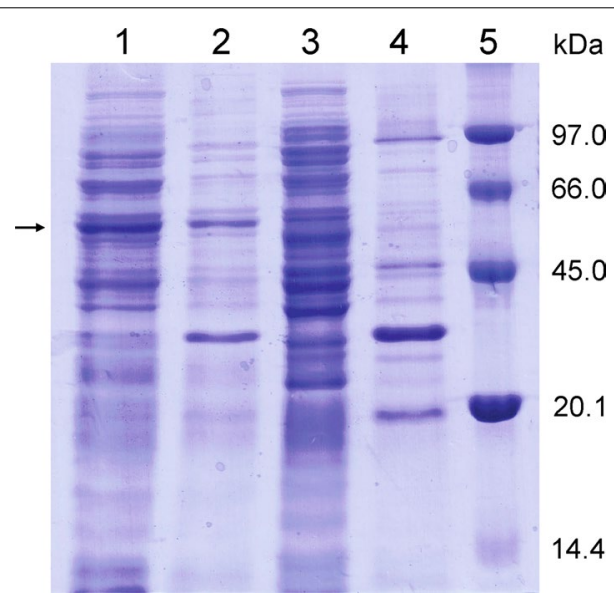

Fig. 2 SDS-PAGE of recombinant $\mathrm{BVMO}_{\text {lepto. }}$ Samples corresponding to the soluble (lane 1) and insoluble (lane 2) fractions of protein extracts of E. coli BL21(DE3)/pHLb01 and the soluble (lane 3) and insoluble (lane 4) fractions of BL21(DE3) protein extract were subjected to $12 \%$ SDS-PAGE followed by Coomassie Blue staining. Lane 5 molecular marker. The arrow indicates the protein band corresponding to the recombinant $\mathrm{BVMO}_{\text {Lepto }}$ in E. coli BL21(DE3) cells, used as controls (Fig. 2, lanes 3 and 4 ). In consequence under the experimental conditions tested, recombinant gene expression yielded the $\mathrm{BVMO}_{\text {Lepto }}$ protein for biotransformations in whole-cell systems.

\section{Assessment of the substrate profile of $\mathrm{BVMO}_{\text {Lepto }}$ as a whole-cell biocatalyst}

In order to evaluate the potential of $\mathrm{BVMO}_{\text {Lepto }}$ as a biocatalyst, we decided to perform whole-cell biotransformation assays. This approach has the advantage of providing NADPH in vivo during the course of reaction. In this study, we aimed at detecting Baeyer-Villiger oxygenation of ketones (Fig. 3). Whole-cells expressing the $\mathrm{BVMO}_{\text {Lepto }}$ were challenged with a collection of ketones with diverse structural characteristics, namely acyclic, cyclic, aromatic, and fused ketones.

In order to explore the ability of this BVMO to oxidize linear- and branched-chain ketones, a set of aliphatic ketones and three alkyl levulinates were tested as substrates. Linear- and branched-chain ketones (1-6) were oxidized with very good conversion and excellent regioselectivity towards the normal ester product formed by the insertion of the oxygen atom on the side of the longer or branched alkyl chain (Table 1). However, cellular lysis or growth inhibition was observed when biotransformations were carried out with the 2-methyloctan-4-one (7) and with nonan-2-one (8) and its derivative 9 under

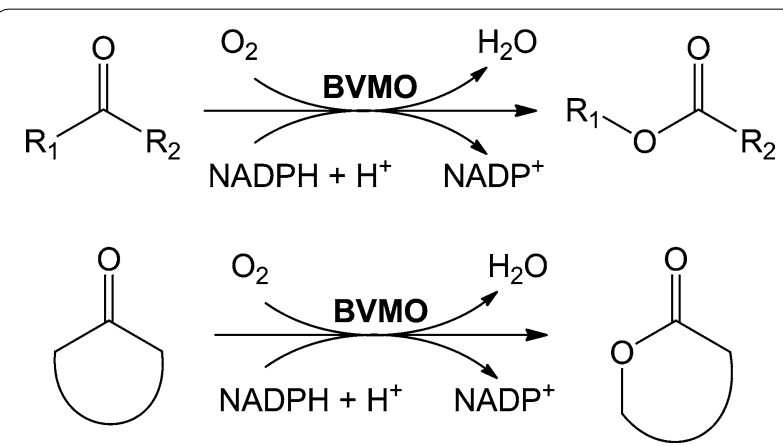

Fig. 3 General Baeyer-Villiger oxidation catalyzed by BVMOs 
Table 1 Biotransformations of linear- and branched-chain ketones mediated by $\mathrm{BVMO}_{\text {Lepto }}$

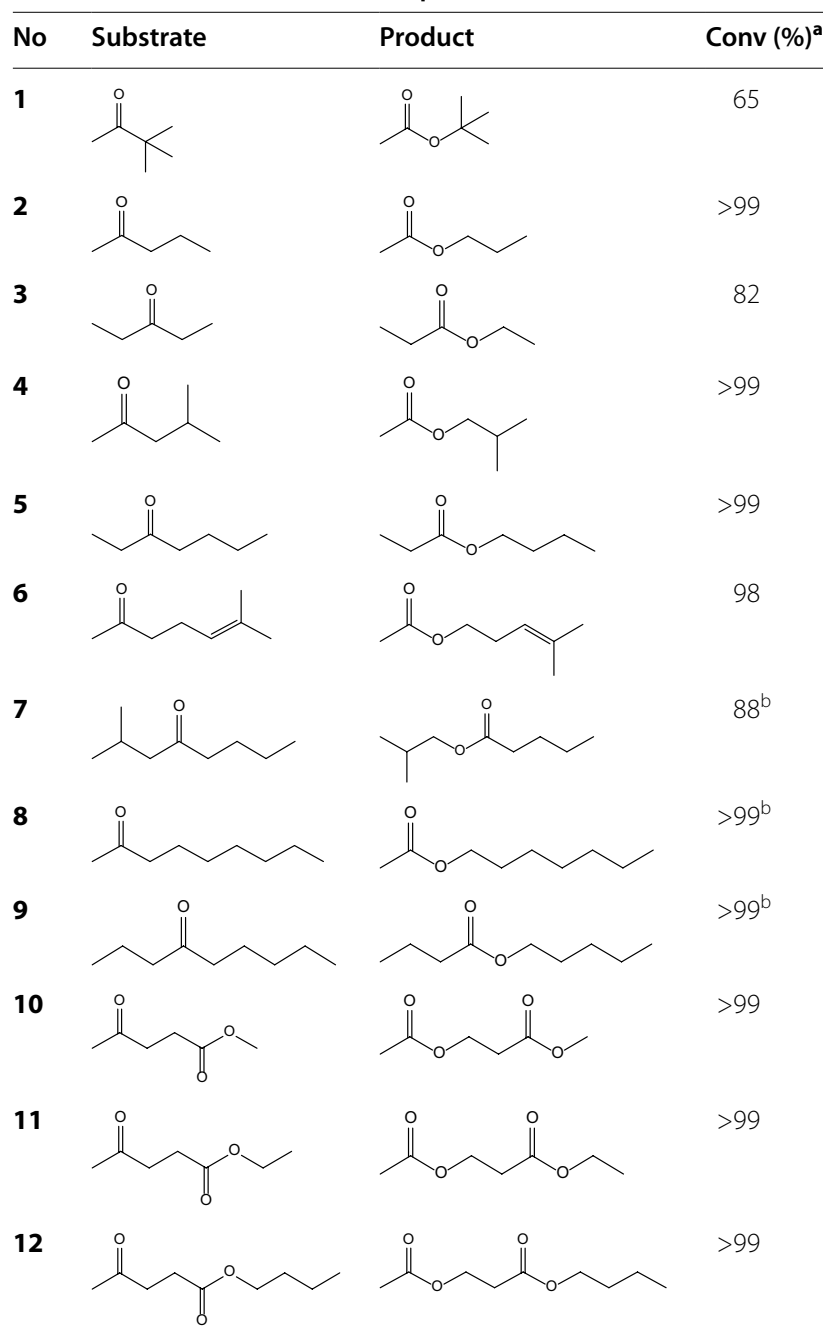

a Relative conversion (Conv) of starting material to ester as determined by GC-FID or GC-MS

b Relative conversion of substrate to ester measured using $0.1 \mathrm{mg} / \mathrm{mL}$ of starting material

standard conditions. In order to overcome this drawback, we decided to lower the concentration of ketones 7,8 and 9 to $0.1 \mathrm{mg} / \mathrm{mL}$. Consequently, excellent conversions of $\mathbf{8}$ and $\mathbf{9}$ were achieved whereas moderate conversion of ketone 7 was detected even at low substrate concentration (Table 1).

The esters shown in Table 1, entries 1-9 (i.e. tert-butyl acetate, propyl acetate, ethyl propionate, isobutyl acetate, butyl propionate, 4-methylpent-3-en-1-yl acetate, heptyl acetate, pentyl butyrate) are important aroma compounds, pesticides or solvents of great interest for the industry. Conventional procedures for the synthesis of these esters involve the use of chemical catalysts, organic solvents, high temperatures and/or refluxing conditions. In contrast, the biooxidation approach towards them is an advantageous alternative to the traditional organic procedures, as high conversions can be achieved by a simple, clean, and efficient method. To the best of our knowledge, this work is the first report of a Baeyer-Villiger biooxidation of ketones 1, 3-7 and 9 to afford their valuable normal esters. Alkyl levulinates 10, 11 and 12 were readily accepted and oxidized by the $\mathrm{BVMO}_{\text {Lepto }}$ biocatalyst with excellent conversion (>99\%) and selectivity, producing only substituted propionates (Table 1 ). These compounds can be easily hydrolyzed to 3-hydroxypropionic acid, which is considered as a value-added chemical precursor or building block for several bulk chemicals.

Whole-cells expressing $\mathrm{BVMO}_{\text {Lepto }}$ showed a trend for the oxidation of the aromatic ketones (Table 2). Acetophenone (1-phenylethanone, 13) was not a substrate for the biocatalyst but phenylacetone (1-phenylpropan-2-one, 14), 1-(p-tolyl)propan-2-one (15), 1-phenylbutan-2-one (16), 4-phenylbutan-2-one (17) and 4-(4-hydroxyphenyl)butan-2-one (18) were fully converted to the normal esters $(>99 \%)$. The biooxidations on ketones 14, 15, and 16 give access to benzyl acetate, 4-methylbenzyl acetate or benzyl propionate, respectively, which are highly used in the fragrance, cosmetic

\section{Table 2 Biotransformation of aromatic ketones mediated} by BVMO ${ }_{\text {Lepto }}$

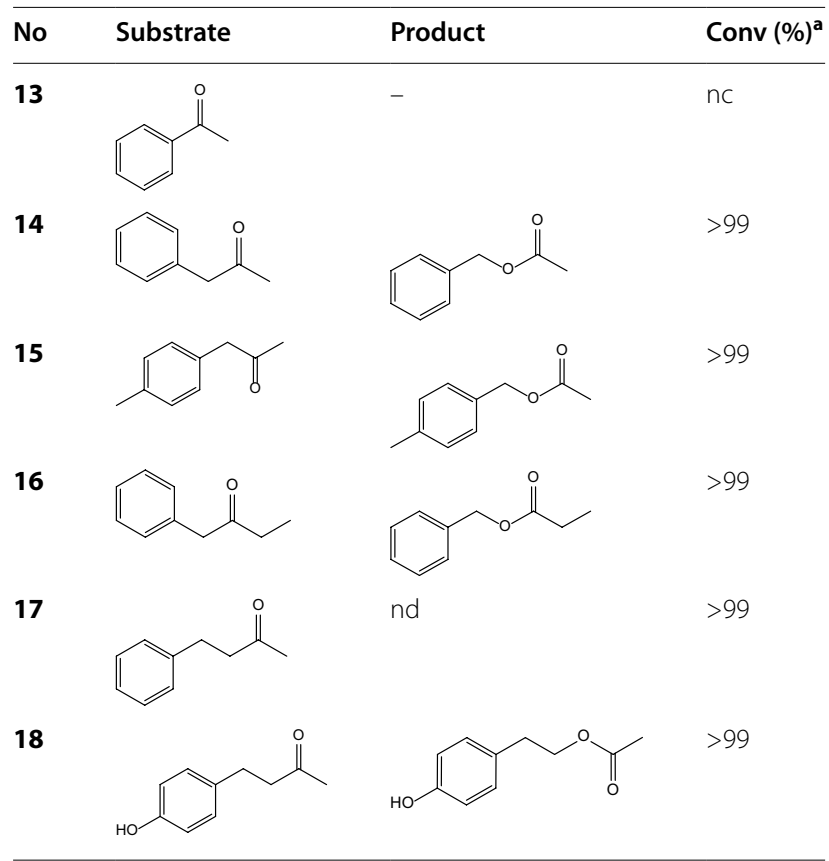

nc no conversion, nd not determined

a Relative conversion (Conv) of starting material to ester as determined by GC-FID or GC-MS 
and food industries as flavor and aroma compounds (McGinty et al. 2012; Surburg and Panten 2006). According to our information, neither 4-methylbenzyl acetate nor benzyl propionate has been obtained by BVMOmediated biooxidations before.

In order to examine the ring size effect of cyclic ketones and the influence of different substituents on the biocatalytic performance of $\mathrm{BVMO}_{\text {Lepto }}$, representative cyclobutanone, cyclopentanone and cyclohexanone derivatives were evaluated as substrates of $\mathrm{BVMO}_{\text {Lepto }}$. The biocatalyst preferred cyclohexanone derivatives with the substitution in position 2 over substituents in position 3 or 4 of the ring (Table 3, compounds 19-25). Oxygen insertion and migration occurred at the more substituted carbon of compounds 19-22, thus giving access to normal lactones exclusively in very good $e e$ with an enantioselectivity trend similar to that observed for CHMO from Acinetobacter sp. NCIMB 9871 (Stewart et al. 1996, 1998). In addition, the set of cyclopentanone derivatives showed an intriguing behavior as well (Table 3). In this series, the 2-benzylcyclopentanone (26) and 3-(2-oxocyclopentyl)propanenitrile (27) were accepted and showed very good conversions but trans3-methyl-2-pentylcyclopentanone (28), 3-methylcyclopent-2-enone (29), and 3-methylcyclopentanone (30) were not substrates for $\mathrm{BVMO}_{\text {Lepto }}$ in whole-cell biotransformations, in agreement with the preference observed for the 2-substituted cyclohexanone derivatives (Table 3). Similarly, the 3-substituted cyclobutanones that are oxidation-prone ketones, were poorly oxidized or not converted at all by $\mathrm{BVMO}_{\text {Lepto }}$ under the assayed conditions (Table 3, compounds 31-33), showing that these ketones are not substrates for this BVMO.

The selectivity of the oxygenation of the fused cyclobutanones was analyzed by chiral phase GC. Figure 4 shows the four possible products of biooxidation on racemic fused cyclobutanones. The oxidation of the racemic cis-bicyclo[3.2.0] hept-2-en-6-one (34) by CHMO from Acinetobacter sp. NCIMB 9871 is a wellknown biotransformation reaction that allows access to approximately 1:1 ratio of normal and abnormal lactones with high optical purities (Alphand and Furstoss 1992). Like the CHMO from Acinetobacter sp. NCIMB 9871, the $\mathrm{BVMO}_{\text {Lepto }}$ oxidized the fused cyclobutanone 34, albeit with poorer ee of both normal (50\%) and abnormal lactones (23\%) (Table 4). Besides, the conversion and regioselectivity of $\mathrm{BVMO}_{\text {Lepto }}$ on ketones 35 and 36 were low but with an unusual trend towards the abnormal lactones. In both cases, abnormal lactones were produced in high optical purity (ee $95 \%$ and $>99 \%$, respectively).
Table 3 Biooxidation of substituted cyclic ketones by BVMO Lepto

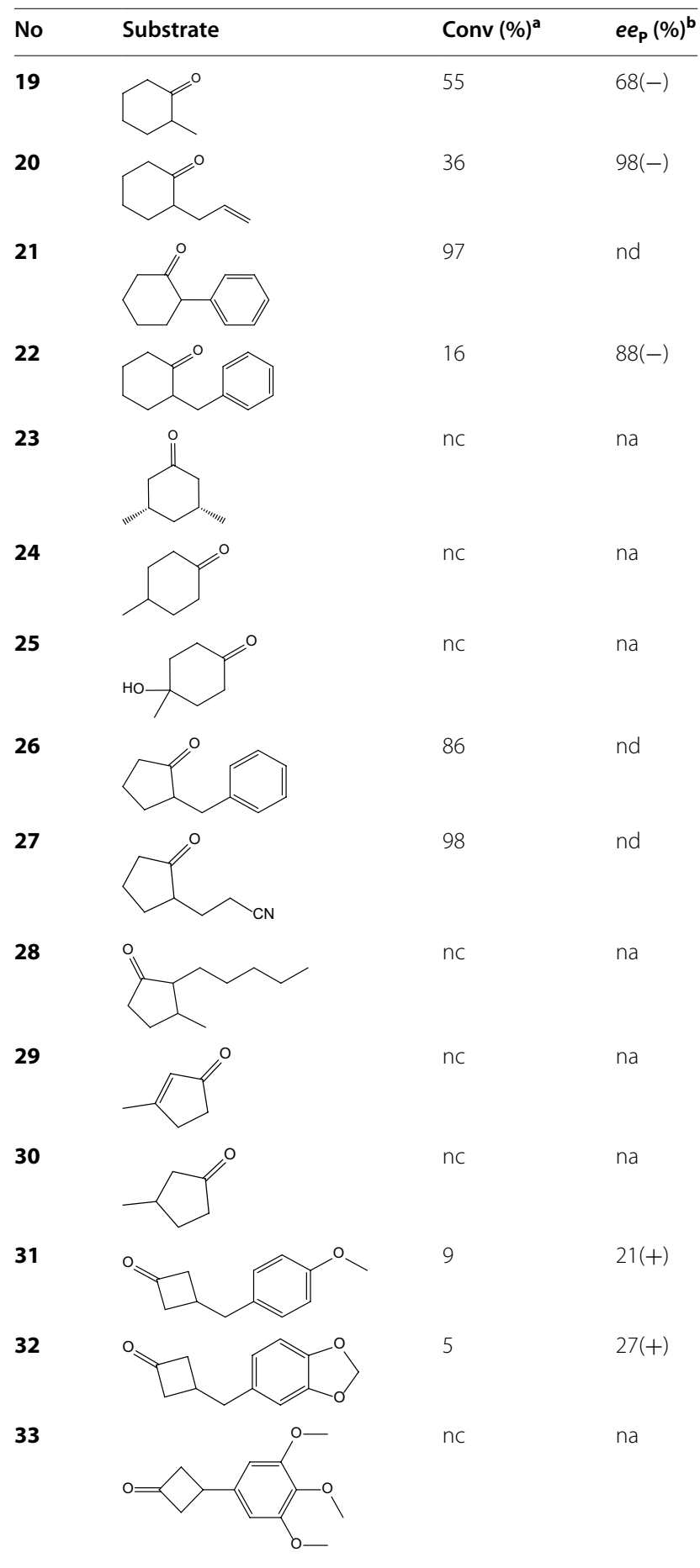

nc no conversion, $n d$ not determined, na not applicable

a Relative conversion (Conv) of starting material to lactone as determined by GC

b Enantiomeric excess of the product (ee $e_{\mathrm{p}}$ ) was determined by chiral phase GC. The sign of specific rotation is indicated in brackets and was assigned according to the literature for reference biotransformations 


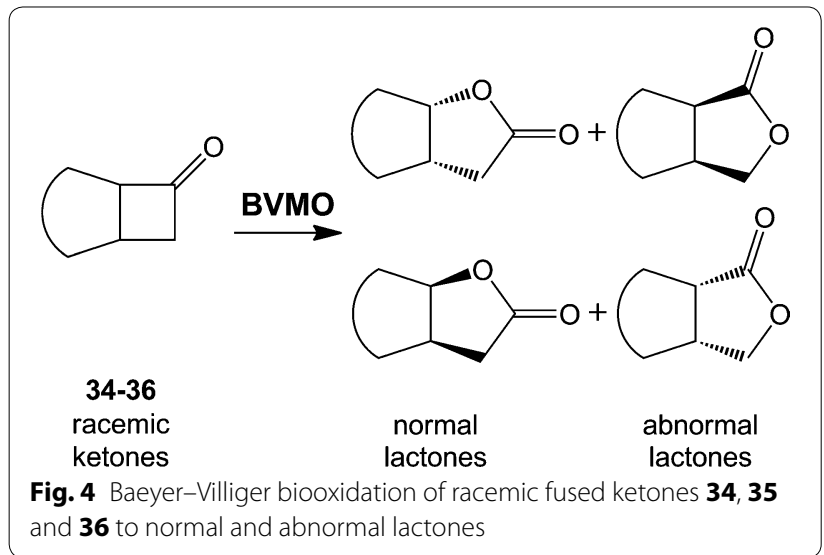

\section{Discussion}

As part of a survey for putative Type I BVMOs sequences in public databases, we investigated the presence of BVMOs in $L$. biflexa by bioinformatic analysis and detected only one gene encoding a Type I BVMO in $L$. biflexa. In this work, we present the Type I BVMO from L. biflexa, its protein sequence analysis and phylogenetic studies. In addition, we report the cloning, heterologous expression in E. coli and biocatalyst assessment of this novel BVMO in whole-cell systems.

The phylogenetic analysis based on known Type I BVMOs indicates that our new $\mathrm{BVMO}_{\text {Lepto }}$ belongs to a clade that remains only partially explored for biocatalysis (Fig. 1a). Indeed, the BVMO ${ }_{\text {Lepto }}$ and the BVMO1 from
M. tuberculosis H37Rv (Accession Number CAA97398) (Bonsor et al. 2006) group together in a subclade of the phylogenetic tree. The $\mathrm{BVMO}_{\text {Lepto }}$ is the first enzyme of this subclade to be functionally produced in E. coli and characterized as a Baeyer-Villiger monooxygenase since the gene coding for BVMO1 from $M$. tuberculosis cloned in plasmid pDB1 was expressed poorly if at all and no activity could be measured with ketones as substrates (Bonsor et al. 2006). The $\mathrm{BVMO}_{\text {Lepto }}$ consists of 488 amino acids and lacks 52 residues that comprise one helical turn and two helices in the polypeptide chain of the CHMO from Rhodococcus sp. HI-31 (Yachnin et al. 2014) as predicted by homology modeling (Additional file 1: Figures S1, S2). This is a feature that $\mathrm{BVMO}_{\text {Lepto }}$ shares with the others BVMOs of the same clade (Fig. 1a). In the crystallographic structure of the CHMO from Rhodococcus sp. HI-31, these helices are exposed to the solvent (Additional file 1: Figure S1). The typical consensus sequences of Type I BVMOs are well conserved in $\mathrm{BVMO}_{\text {Lepto }}$ (Fig. 1b).

The $\mathrm{BVMO}_{\text {Lepto }}$ coding sequence was cloned and overexpressed in E. coli yielding approximately $60 \%$ of soluble recombinant protein (Fig. 2). In order to investigate its substrate scope for possible synthetic applications of this BVMO and to compare its performance with other BVMOs, we have challenged $\mathrm{BVMO}_{\text {Lepto }}$ with a broad variety of ketones of different sizes and bearing diverse functional substituents.

Although some model aliphatic linear ketones have been evaluated as substrates for BVMOs (Beneventi

Table 4 Biooxidation of fused cyclobutanones mediated by BVMO Lepto

\begin{tabular}{|c|c|c|c|c|c|c|}
\hline \multirow[t]{3}{*}{ No } & \multirow[t]{3}{*}{ Substrate } & \multicolumn{2}{|c|}{ BVMO Leptospira biflexa } & \multicolumn{3}{|c|}{$\begin{array}{l}\text { Reference biotransformation using CHMO Acinetobacter sp. NCIMB } \\
9871 \text { as biocatalyst }\end{array}$} \\
\hline & & Conv $^{\mathrm{a}}(\%)$ & $e e_{N}, e e_{A B N}(\%)^{b}$ & Yield (\%) & $e e_{N^{\prime}} e e_{A B N}(\%)^{b}$ & References \\
\hline & & $\mathrm{N}: \mathrm{ABN}(\%)$ & & $\mathrm{N}: \mathrm{ABN}(\%)$ & & \\
\hline \multirow[t]{2}{*}{34} & & 94 & $50(-), 23(-)$ & 74 & $95(-),>99(-)$ & Mihovilovic et al. (2005b) \\
\hline & & $50: 50$ & & $51: 49$ & & \\
\hline \multirow[t]{2}{*}{35} & & 8 & $44(-), 95(-)$ & 80 & $60(-),>95(-)$ & Alphand and Furstoss (1992) \\
\hline & & $27: 73$ & & $65: 35$ & & \\
\hline \multirow[t]{2}{*}{36} & & 47 & $96(\mathrm{nd}),>99(\mathrm{nd})$ & 84 & 44(nd), >99(nd) & Mihovilovic et al. (2008) \\
\hline & & 19:81 & & 70:30 & & \\
\hline
\end{tabular}

$N: A B N$ ratio of normal:abnormal lactones, $n d$ not determined

a Relative conversion (Conv) of starting material to lactone as determined by chiral phase GC

b Enantiomeric excess for normal lactone $\left(e e_{\mathrm{N}}\right)$ and abnormal lactone $\left(e e_{\mathrm{ABN}}\right)$. The sign of specific rotation is indicated in brackets and was assigned according to the literature for reference biotransformations 
et al. 2013; Bisagni et al. 2014a, b; Bonsor et al. 2006; Ferroni et al. 2014; Fraaije et al. 2004; Kirschner et al. 2007; Kotani et al. 2007; Rehdorf et al. 2007, 2009, 2010a, b; Riebel et al. 2012; Szolkowy et al. 2009; van Beek et al. 2014; Völker et al. 2008), in this work, we present a systematic analysis of $\mathrm{BVMO}_{\text {Lepto }}$-mediated biooxidations of a broad range of unsubstituted linear ketones, linearbranched ketones and linear ketones with aromatic substituents. To the best of our knowledge, about half of the ketones shown in Tables 1 and 2 have never been reported as BVMO substrates before.

Amongst the tested linear and linear-branched ketones, this biocatalyst showed a clear preference towards medium-length, linear- and branched-chain ketones as substrates, reaching full conversions in most cases under standard biotransformation experiments. These reactions proceeded with excellent selectivity as judged by the insertion of the oxygen atom on the side of the longer or branched alkyl chain, producing the so-called normal regioisomeric ester in each case only (Table 1). Only pentan-2-one and nonan-2-one out of the ketones listed in Table 1, had been evaluated as substrates for BVMOs in previous years (Bisagni et al. 2014b; Kotani et al. 2007; Rehdorf et al. 2007; Völker et al. 2008). So far, the biooxidation of penta-2-one have been measured following the consumption of NADPH at $340 \mathrm{~nm}$ in vitro (Kotani et al. 2007; Völker et al. 2008). Similarly to $\mathrm{BVMO}_{\text {Lepto }}$-mediated biotransformation, the BVMO3 from Dietzia sp. D5 (Bisagni et al. 2014b) and the BVMO from P. putida KT2440 (Rehdorf et al. 2007) oxidized nonan-2-one to heptyl acetate. On the other hand, Bisagni et al. (2014b) reported the formation of normal and abnormal esters of 3-keto substrates by the BVMO3 from Dietzia sp. D5. In $\mathrm{BVMO}_{\text {Lepto }}$-mediated biooxidations of ketones 5, 7 and 9, the keto group at the second, third or fourth $\mathrm{C}$-atom did not affect regioselectivity since the corresponding normal esters were obtained in all cases with excellent conversions after $24 \mathrm{~h}$ of biotransformation (Table 1). When we explored the biotransformation of 2-methyloctan-4-one (7), nonan-2-one (8) and its derivative 9 under standard conditions, we detected cellular lysis or growth inhibition. A similar observation had been reported for the biooxidation of nonan-2-one by the BVMO from P. putida KT2440 under growing conditions but, in that case, the authors observed no cellular growth and no conversion of the ketone (Rehdorf et al. 2007). By reducing the concentration of ketones 7, 8 and 9 in the biotransformation reactions, we were able to achieve high conversions (Table 1).

Levulinic esters are valuable precursors of the 3-hydroxypropionic acid, a versatile compound which may be employed as platform chemical for the synthesis of 1,3-propanediol, acrylamide, acrylic acid and methyl acrylate, among others. The 3-hydroxypropionic acid can be synthesized chemically and biologically as reviewed in (Kumar et al. 2013). Besides, the enzyme-mediated Baeyer-Villiger oxidation of levulinic esters followed by hydrolysis may enable a perspective for a practical and simple alternative to produce 3-hydroxypropionic acid. In this context, the biocatalytic Baeyer-Villiger oxidation of alkyl levulinates in water under ambient conditions was demonstrated recently (Fink and Mihovilovic 2015). In the same work, it was also shown the Baeyer-Villiger oxidation of ethyl levulinate on gram scale to afford ethyl 3-acetoxypropionate (Fink and Mihovilovic 2015). In that study, 13 different BVMOs were evaluated on three alkyl levulinates. The best results were obtained with CPMO from Comamonas sp. NCIMB 9872 and CDMO from $R$. ruber $\mathrm{SC} 1$ on butyl levulinate ( 90-95\% conversion), although their activity on methyl or ethyl levulinates was moderate (Fink and Mihovilovic 2015). In the present work, we observed that the $\mathrm{BVMO}_{\text {Lepto }}$, which is distantly related to CPMO from Comamonas sp. NCIMB 9872 and CDMO from $R$. ruber SC1, was able to accept and oxidize levulinic esters with excellent conversion (>99\%) and selectivity (Table 1 ) allowing easy access to pure propionates derivatives, thus providing a very interesting alternative tool for these biotransformations.

In addition, all tested linear ketones with aromatic substituents, except acetophenone (13), were excellent substrates for $\mathrm{BVMO}_{\text {Lepto }}$ (Table 2). Acetophenone is not a substrate for CHMO from Acinetobacter sp. NCIMB 9871 either, although it has been accepted by three fungal BVMOs from Aspergillus flavus NRRL3357 (Ferroni et al. 2014) and by HAPMO from $P$. fluorescens ACB (Kamerbeek et al. 2003). This preference against acetophenone derivatives and for phenylacetone (14) is not novel, since the well-known PAMO from T. fusca showed the same behavior (Fraaije et al. 2005). To our knowledge, this is the first work that reports the synthesis of 4-methylbenzyl acetate or benzyl propionate by BVMOmediated biotransformations of ketones $\mathbf{1 5}$ or 16. In the series shown in Table 2, it is clear that $\mathrm{BVMO}_{\text {Lepto }}$ oxidizes linear aromatic ketones with insertion of the oxygen atom to the more substituted carbon. In the case of 1-phenylbutan-2-one (16), where both $\alpha$-carbon atoms are equally substituted, the migratory aptitude of the $\alpha$-carbon atoms seemed to be primarily determined by the higher nucleophilicity of the $\alpha$-carbon bonded to the aromatic ring due to its donating electronic effect compared with the methyl group. The 4-phenylbutan-2-one (17) and the 4-(4-hydroxyphenyl)butan-2-one (18) have been evaluated as substrates on the four BVMOs from A. flavus NRRL3357 (Ferroni et al. 2014). The authors reported that longer distances between the carbonyl group and the aromatic ring, and a hydroxy substitution 
on the para position of the ring resulted in relative low conversions for some of the enzymes. However, these features did not affect the excellent conversions observed with $\mathrm{BVMO}_{\text {Lepto }}$ after $24 \mathrm{~h}$, indicating that it may be the best biocatalyst for this kind of transformations reported to date.

In this work, we present biotransformation results after $24 \mathrm{~h}$ of reaction. Although kinetic resolution processes could be possible for racemic substrates, these studies might be the matter of future research. Amongst the series of cyclic ketones, it is worth noting that the oxidation of cyclohexanone derivatives was very selective towards structures with substituents in $\alpha$-position to the carbonyl group, as evidenced by the lack of reaction on 3,5-dimethylcyclohexanone (23), 4-methylcyclohexanone (24) or 4-hydroxy-4-methylcyclohexanone (25) (Table 3). A similar substitution preference was observed for the oxidation of mono- and disubstituted cyclopentanones (26-30) (Table 3). The BVMO4 from Dietzia sp. D5 also revealed a decrease in activity in the series of 2-, 3- and 4-methylcylohexanones by spectrophotometric measurements (Bisagni et al. 2014a). However, this is not a general behavior since oxidations of 3- or 4-substituted cyclohexanones are well-established reactions for the typical cycloketones-converting BVMOs such as CHMO from Acinetobacter sp. NCIMB 9871 (Mihovilovic et al. 2001; Stewart et al. 1998; Taschner and Black 1988), CHMO from Xanthobacter sp. ZL5 (Rial et al. 2008a, b), CPMO from Comamonas sp. NCIMB 9872 (Iwaki et al. 2002), CDMO from $R$. ruber SC1 (Fink et al. 2012), CPDMO from Pseudomonas sp. strain HI-70 (Fink et al. 2011; Iwaki et al. 2006), and CHMO from Polaromonas sp. strain JS666 (Alexander et al. 2012). Therefore, the strict selection against substituents in position 3 and 4 of the ring seems to be a unique behavior of $\mathrm{BVMO}_{\text {Lepto }}$ since to the best of our knowledge, such clear selectivity has never been reported for another BVMO before. These intriguing results led us to consider conducting three-dimensional protein studies and molecular docking simulations in the future in order to investigate the steric hindrance that prevent interaction of these substrates with the enzyme and shed some light on the mode of their binding to the active site of $\mathrm{BVMO}_{\text {Lepto }}$. In line with these observations, the 3 -substituted cyclobutanones tested (31-33) were very poor substrates or not substrates at all for $\mathrm{BVMO}_{\text {Lepto }}$ (Table 3). BVMOs that cluster together with $\mathrm{BVMO}_{\text {Lepto }}$ have never been evaluated on these ketones before, thus available data correspond to distant BVMOs. The HAPMO from P. fluorescens ACB is the phylogenetically closest BVMO that has been evaluated on ketones 31 and 32; this enzyme showed modest yield and ee for the desymmetrization of $\mathbf{3 1}$ and $\mathbf{3 2}$ (Mihovilovic et al. 2005a). However, the CHMO-type enzymes, which belong to the phylogenetic group III, readily catalyze the desymmetrization of prochiral ketones 31-33 to the corresponding lactones with high ee (Alexander et al. 2012; Alphand et al. 1998; Rial et al. 2008a; Rudroff et al. 2007). The racemic cis-bicyclo[3.2.0]hept-2-en-6-one (34) is a well-known substrate for $\mathrm{CHMO}$ from Acinetobacter sp. NCIMB 9871 and for many other BVMOs (Alexander et al. 2012; Alphand and Furstoss 1992; Ferroni et al. 2014; Fink et al. 2011; Mihovilovic et al. 2005b, 2008; Rial et al. 2008b). After $24 \mathrm{~h}$, the $\mathrm{BVMO}_{\text {Lepto }}$ oxidized this racemic substrate almost completely to equal amounts of normal and abnormal lactones (Fig. 4) but, unlike CHMO from Acinetobacter sp. NCIMB 9871, the ee of each regioisomeric lactone was poor (Table 4), The oxidation of the fused ketone 35 or 36 by $\mathrm{BVMO}_{\text {Lepto }}$ preferentially gave abnormal lactones. These compounds (35 or 36) have been reported as substrates on approximately 10 Type I BVMOs, and in all cases except the BVMO5 from M. tuberculosis H37Rv (Snajdrova et al. 2006), approximately equal amounts of regioisomeric lactones or normal lactones have been preferentially produced (Alphand and Furstoss 1992; Fink et al. 2012; Mihovilovic et al. 2005a, 2008; Rial et al. 2008b).

The substrate scope of the enzymes that locate to the clade of the phylogenetic tree together with $\mathrm{BVMO}_{\text {Lepto }}$ (Fig. 1a) is still unclear due to the little information available regarding these enzymes. Nevertheless, particular observations about the substrate profile of some of them are worth noting. The BVMO5 from $M$. tuberculosis $\mathrm{H} 37 \mathrm{Rv}$ is the only previous report of a BVMO able to oxidize ketones $\mathbf{3 5}$ and $\mathbf{3 6}$ preferentially to the abnormal lactones (Snajdrova et al. 2006). Besides, the BVMO from P. fluorescens DSM 50106 showed a narrow substrate profile with high selectivity towards aliphatic open-chain ketones $\left(\mathrm{C}_{8}, \mathrm{C}_{10}\right)$, but no cyclic or aromatic ketones were accepted (Kirschner et al. 2007). Other members, such as the previously mentioned BVMO5 from $M$. tuberculosis $\mathrm{H} 37 \mathrm{Rv}$ or the BVMOs 2, 5 and 19 from $R$. jostii also accepted aliphatic open-chain ketones (Bonsor et al. 2006; Riebel et al. 2012). Despite the fact that the ability to oxidize linear ketones is not exclusively limited to enzymes of this clade, a certain preference for them could be a common feature of these BVMOs.

In summary, we selected the novel $\mathrm{BVMO}_{\text {Lepto }}$ as a representative enzyme to explore the subclade shown in green in the phylogenetic tree of the current BVMOs (Fig. 1a), which had never been experimentally approached before. Thus, this work represents the first report of a confirmed BVMO that belongs to that subclade. The recombinant $\mathrm{BVMO}_{\text {Lepto }}$ accepted 28 out of the 36 reported ketones in whole-cell biotransformations. Our results indicate that $\mathrm{BVMO}_{\text {Lepto }}$ catalyzes the oxidation of linear- and branched- small and medium-length 
ketones as well as alkyl levulinates with excellent regioselectivity towards the corresponding normal esters, representing a very attractive biocatalyst for these transformations. This trend is conserved for linear aromatic ketones, except for acetophenone that it is not a substrate. Even though the cyclic and fused ketones tested seem to be moderate substrates, $\mathrm{BVMO}_{\text {Lepto }}$ was selective towards cycloketones with substituents in $\alpha$-position to the carbonyl group and against other substitution patterns. This selective behavior will be the object of future studies.

\section{Additional file}

Additional file 1: Table S1. BVMO sequences used to infer the phylogenetic tree. Figure S1. Multiple sequence alignment of $\mathrm{BVMO}_{\text {Lepto }}$ and representative BVMOs belonging to different clades. Figure S2. Homology modeling of the BVMO from L. biflexa.

\section{Abbreviations}

BVMO: Baeyer-Villiger monooxygenase; $\mathrm{BVMO}_{\text {Lepto }}$ : Baeyer-Villiger monooxygenase from Leptospira biflexa; CDMO: cyclododecanone monooxygenase; CHMO: cyclohexanone monooxygenase: CPMO: cyclopentanone monooxygenase; DNA: deoxyribonucleic acid; ee: enantiomeric excess; FAD: flavin adenine dinucleotide; GC-MS: gas chromatography-mass spectrometry; HAPMO: 4-hydroxyacetophenone monooxygenase; IPTG: isopropyl $\beta$-D-1thiogalactopyranoside; LB: Luria-Bertani; na: not applicable; NADPH: reduced nicotinamide adenine dinucleotide phosphate; nc: no conversion; nd: not determined; PAMO: phenylacetonone monooxygenase; OD: optical density; PCR: polymerase chain reaction; SDS-PAGE: sodium dodecyl sulfate-polyacrylamide gel electrophoresis.

\section{Authors' contributions}

RDC performed the bioinformatic and experimental work, GC data analysis and helped to draft the manuscript. DAB contributed with materials and analysis tools, and participated in the design of the substrate profiling. MJF contributed to GC data collection and analysis. MDM contributed with materials, analysis tools, and strains for reference biotransformations. DVR conceived the experiments, participated in the design and coordination of the work and wrote most of the manuscript. All authors discussed the results and edited the final manuscript. All authors read and approved the final manuscript.

\section{Author details}

1 Área Biología Molecular, Departamento de Ciencias Biológicas, Facultad de Ciencias Bioquímicas y Farmacéuticas, Universidad Nacional de Rosario, CONICET, Suipacha 531, S2002LRK Rosario, Argentina. ${ }^{2}$ Instituto de Química Rosario (IQUIR, CONICET-UNR), Facultad de Ciencias Bioquímicas y Farmacéuticas, Universidad Nacional de Rosario, Suipacha 531 S2002LRK, Rosario, Argentina. ${ }^{3}$ Institute of Applied Synthetic Chemistry, Vienna University of Technology, Getreidemarkt 9/163, 1060 Vienna, Austria. ${ }^{4}$ Present Address: Department of Chemistry and Chemical Biology, Harvard University, Cambridge, MA, USA.

\section{Acknowledgements}

We thank Prof. Dr. Eduardo A. Ceccarelli (Instituto de Biología Molecular y Celular de Rosario, CONICET-UNR, Rosario, Argentina) and Prof. Mathieu Picardeau (Unité de Biologie des Spirochètes, Institut Pasteur, Paris, France) for kindly providing the genomic DNA of Leptospira biflexa. We would also like to thank Guillermo Marcuzzi (CCT-Rosario CONICET) for his help with GC measurements.

\section{Competing interests}

The authors declare that they have no competing interests.

\section{Availability of data and materials}

The datasets supporting the conclusions of this article are included within the article and its Additional file 1.

\section{Funding}

This work was supported by Agencia Nacional de Promoción Científica y Tecnológica (ANPCyT; PRH 24 PICT 2009-0088), Consejo Nacional de Investigaciones Científicas y Técnicas (CONICET; PIP 11220110101156 , PIP 11220150100934) and Universidad Nacional de Rosario (UNR; BIO287, BIO339) in Argentina, and Austrian Science Fund FWF (1723-N17) in Austria. The Programa de Ayuda para Viajes al Exterior (AVE) from UNR, Argentina, is acknowledged for the financial support granted to RDC and DVR.

\section{Publisher's Note}

Springer Nature remains neutral with regard to jurisdictional claims in published maps and institutional affiliations.

Received: 11 April 2017 Accepted: 21 April 2017

Published online: 27 April 2017

\section{References}

Alexander AK, Biedermann D, Fink MJ, Mihovilovic MD, Mattes TE (2012) Enantioselective oxidation by a cyclohexanone monooxygenase from the xenobiotic-degrading Polaromonas sp. strain JS666. J Mol Catal B Enzym 78:105-110

Alphand V, Furstoss R (1992) Microbiological transformations. 22. Microbiologically mediated Baeyer-Villiger reactions: a unique route to several bicyclic Y-lactones in high enantiomeric purity. J Org Chem 57:1306-1309

Alphand V, Mazzini C, Lebreton J, Furstoss R (1998) A new microorganism for highly stereospecific Baeyer-Villiger oxidation of prochiral cyclobutanones. J Mol Catal B Enzym 5:219-221

Balke K, Kadow M, Mallin H, Sass S, Bornscheuer UT (2012) Discovery, application and protein engineering of Baeyer-Villiger monooxygenases for organic synthesis. Org Biomol Chem 10:6249-6265

Beneventi E, Niero M, Motterle R, Fraaije MW, Bergantino E (2013) Discovery of Baeyer-Villiger monooxygenases from photosynthetic eukaryotes. J Mol Catal B Enzym 98:145-154

Bianchi DA, Moran-Ramallal R, Iqbal N, Rudroff F, Mihovilovic MD (2013) Enantiocomplementary access to carba-analogs of $\mathrm{C}$-nucleoside derivatives by recombinant Baeyer-Villiger monooxygenases. Bioorg Med Chem Lett 23:2718-2720

Bisagni S, Hatti-Kaul R, Mamo G (2014a) Cloning, expression and characterization of a versatile Baeyer-Villiger monooxygenase from Dietzia sp. D5. AMB Express 4:23

Bisagni S, Smuś J, Chávez G, Hatti-Kaul R, Mamo G (2014b) Cloning and expression of a Baeyer-Villiger monooxygenase oxidizing linear aliphatic ketones from Dietzia sp. D5. J Mol Catal B Enzym 109:161-169

Bonsor D, Butz SF, Solomons J, Grant S, Fairlamb IJ, Fogg MJ, Grogan G (2006) Ligation independent cloning (LIC) as a rapid route to families of recombinant biocatalysts from sequenced prokaryotic genomes. Org Biomol Chem 4:1252-1260

Bučko M, Gemeiner P, Schenkmayerová A, Krajčovič T, Rudroff F, Mihovilovič MD (2016) Baeyer-Villiger oxidations: biotechnological approach. Appl Microbiol Biotechnol 100:6585-6599

Ceccoli RD, Bianchi DA, Rial DV (2014) Flavoprotein monooxygenases for oxidative biocatalysis: recombinant expression in microbial hosts and applications. Front Microbiol 5:25

de Gonzalo G, Mihovilovic MD, Fraaije MW (2010) Recent developments in the application of Baeyer-Villiger monooxygenases as biocatalysts. ChemBioChem 11:2208-2231

Ferroni FM, Smit MS, Opperman DJ (2014) Functional divergence between closely related Baeyer-Villiger monooxygenases from Aspergillus flavus. J Mol Catal B Enzym 107:47-54

Fink MJ, Mihovilovic MD (2015) Non-hazardous Baeyer-Villiger oxidation of levulinic acid derivatives: alternative renewable access to 3-hydroxypropionates. Chem Commun 51:2874-2877 
Fink MJ, Fischer TC, Rudroff F, Dudek H, Fraaije MW, Mihovilovic MD (2011) Extensive substrate profiling of cyclopentadecanone monooxygenase as Baeyer-Villiger biocatalyst reveals novel regiodivergent oxidations. J Mol Catal B Enzym 73:9-16

Fink MJ, Rial DV, Kapitanova P, Lengar A, Rehdorf J, Cheng Q, Rudroff F, Mihovilovic MD (2012) Quantitative comparison of chiral catalysts selectivity and performance: a generic concept illustrated with cyclododecanone monooxygenase as Baeyer-Villiger biocatalyst. Adv Synth Catal 354:3491-3500

Fink MJ, Schön M, Rudroff F, Schnürch M, Mihovilovic MD (2013) Single operation stereoselective synthesis of aerangis lactones: combining continuous flow hydrogenation and biocatalysts in a chemoenzymatic sequence. ChemCatChem 5:724-727

Fraaije MW, Kamerbeek NM, Heidekamp AJ, Fortin R, Janssen DB (2004) The prodrug activator EtaA from Mycobacterium tuberculosis is a Baeyer-Villiger monooxygenase. J Biol Chem 279:3354-3360

Fraaije MW, Wu J, Heuts DP, van Hellemond EW, Spelberg JH, Janssen DB (2005) Discovery of a thermostable Baeyer-Villiger monooxygenase by genome mining. Appl Microbiol Biotechnol 66:393-400

Guindon S, Dufayard JF, Lefort V, Anisimova M, Hordijk W, Gascuel O (2010) New algorithms and methods to estimate maximum-likelihood phylogenies: assessing the performance of PhyML 3.0. Syst Biol 59:307-321

Houben K, Marion D, Tarbouriech N, Ruigrok RW, Blanchard L (2007) Interaction of the $\mathrm{C}$-terminal domains of sendai virus $\mathrm{N}$ and $\mathrm{P}$ proteins: comparison of polymerase-nucleocapsid interactions within the paramyxovirus family. JVirol 81:6807-6816

Iwaki H, Hasegawa Y, Wang S, Kayser MM, Lau PC (2002) Cloning and characterization of a gene cluster involved in cyclopentanol metabolism in Comamonas sp. strain NCIMB 9872 and biotransformations effected by Escherichia coli-expressed cyclopentanone 1,2-monooxygenase. Appl Environ Microbiol 68:5671-5684

Iwaki H, Wang S, Grosse S, Bergeron H, Nagahashi A, Lertvorachon J, Yang J, Konishi Y, Hasegawa Y, Lau PC (2006) Pseudomonad cyclopentadecanone monooxygenase displaying an uncommon spectrum of Baeyer-Villiger oxidations of cyclic ketones. Appl Environ Microbiol 72:2707-2720

Kamerbeek NM, Olsthoorn AJ, Fraaije MW, Janssen DB (2003) Substrate specificity and enantioselectivity of 4-hydroxyacetophenone monooxygenase. Appl Environ Microbiol 69:419-426

Katoh K, Standley DM (2013) MAFFT multiple sequence alignment software version 7: improvements in performance and usability. Mol Biol Evol 30:772-780

Kirschner A, Altenbuchner J, Bornscheuer UT (2007) Cloning, expression, and characterization of a Baeyer-Villiger monooxygenase from Pseudomonas fluorescens DSM 50106 in E. coli. Appl Microbiol Biotechnol 73:1065-1072

Kotani T, Yurimoto H, Kato N, Sakai Y (2007) Novel acetone metabolism in a propane-utilizing bacterium, Gordonia sp. strain TY-5. J Bacteriol 189:886-893

Kumar V, Ashok S, Park S (2013) Recent advances in biological production of 3-hydroxypropionic acid. Biotechnol Adv 31:945-961

Leisch H, Morley K, Lau PC (2011) Baeyer-Villiger monooxygenases: more than just green chemistry. Chem Rev 111:4165-4222

McGinty D, Letizia CS, Api AM (2012) Fragrance material review on 4-methylbenzyl acetate. Food Chem Toxicol 50:S475-S478

Mihovilovic MD, Chen G, Wang S, Kyte B, Rochon F, Kayser MM, Stewart JD (2001) Asymmetric Baeyer-Villiger oxidations of 4-mono- and 4,4-disubstituted cyclohexanones by whole cells of engineered Escherichia coli. J Org Chem 66:733-738

Mihovilovic MD, Kapitan P, Rydz J, Rudroff F, Ogink FH, Fraaije MW (2005a) Biooxidation of ketones with a cyclobutanone structural motif by recombinant whole-cells expressing 4-hydroxyacetophenone monooxygenase. J Mol Catal B Enzym 32:135-140

Mihovilovic MD, Rudroff F, Grötzl B, Kapitan P, Snajdrova R, Rydz J, Mach R (2005b) Family clustering of Baeyer-Villiger monooxygenases based on protein sequence and stereopreference. Angew Chem Int Ed 44:3609-3613

Mihovilovic MD, Bianchi DA, Rudroff F (2006) Accessing tetrahydrofuran-based natural products by microbial Baeyer-Villiger biooxidation. Chem Commun 2006:3214-3216

Mihovilovic MD, Kapitan P, Kapitanova P (2008) Regiodivergent Baeyer-Villiger oxidation of fused ketones by recombinant whole-cell biocatalysts. Chemsuschem 1:143-148
Oberleitner N, Peters C, Muschiol J, Kadow M, Saß S, Bayer T, Schaaf P, lqbal N, Rudroff F, Mihovilovic MD, Bornscheuer UT (2013) An enzymatic toolbox for cascade reactions: a showcase for an in vivo redox sequence in asymmetric synthesis. ChemCatChem 5:3524-3528

Oberleitner N, Peters C, Rudroff F, Bornscheuer UT, Mihovilovic MD (2014) In vitro characterization of an enzymatic redox cascade composed of an alcohol dehydrogenase, an enoate reductases and a Baeyer-Villiger monooxygenase. J Biotechnol 192:393-399

Oberleitner N, Ressmann A, Bica K, Gärtner P, Fraaije MW, Bornscheuer U, Rudroff F, Mihovilovic M (2017) From waste to value: direct utilization of limonene from orange peel in a biocatalytic cascade reaction towards chiral carvolactone. Green Chem 19:367-371

Picardeau M, Bulach DM, Bouchier C, Zuerner RL, Zidane N, Wilson PJ, Creno S, Kuczek ES, Bommezzadri S, Davis JC, McGrath A, Johnson MJ, Boursaux-Eude C, Seemann T, Rouy Z, Coppel RL, Rood JI, Lajus A, Davies JK, Médigue C, Adler B (2008) Genome sequence of the saprophyte Leptospira biflexa provides insights into the evolution of Leptospira and the pathogenesis of leptospirosis. PLoS ONE 3:e1607

Rambaut A, Drummond A (2010) FigTree 1.3.1. Institute of Evolutionary Biology, University of Edinburgh. http://tree.bio.ed.ac.uk/

Rehdorf J, Kirschner A, Bornscheuer UT (2007) Cloning, expression and characterization of a Baeyer-Villiger monooxygenase from Pseudomonas putida KT2440. Biotechnol Lett 29:1393-1398

Rehdorf J, Lengar A, Bornscheuer UT, Mihovilovic MD (2009) Kinetic resolution of aliphatic acyclic $\beta$-hydroxyketones by recombinant whole-cell Baeyer-Villiger monooxygenases-formation of enantiocomplementary regioisomeric esters. Bioorg Med Chem Lett 19:3739-3743

Rehdorf J, Mihovilovic MD, Bornscheuer UT (2010a) Exploiting the regioselectivity of Baeyer-Villiger monooxygenases for the formation of $\beta$-amino acids and $\beta$-amino alcohols. Angew Chem Int Ed 49:4506-4508

Rehdorf J, Mihovilovic MD, Fraaije MW, Bornscheuer UT (2010b) Enzymatic synthesis of enantiomerically pure $\beta$-amino ketones, $\beta$-amino esters, and $\beta$-amino alcohols with Baeyer-Villiger monooxygenases. Chemistry 16:9525-9535

Rial DV, Bianchi DA, Kapitanova P, Lengar A, van Beilen JB, Mihovilovic MD (2008a) Stereoselective desymmetrizations by recombinant whole cells expressing the Baeyer-Villiger monooxygenase from Xanthobacter sp. ZL5: a new biocatalyst accepting structurally demanding substrates. Eur J Org Chem 2008:1203-1213

Rial DV, Cernuchova P, van Beilen JB, Mihovilovic MD (2008b) Biocatalyst assessment of recombinant whole-cells expressing the Baeyer-Villiger monooxygenase from Xanthobacter sp. ZL5. J Mol Catal B Enzym 50:61-68

Riebel A, Dudek HM, de Gonzalo G, Stepniak P, Rychlewski L, Fraaije MW (2012) Expanding the set of rhodococcal Baeyer-Villiger monooxygenases by high-throughput cloning, expression and substrate screening. Appl Microbiol Biotechnol 95:1479-1489

Rudroff F, Rydz J, Ogink FH, Fink M, Mihovilovic MD (2007) Comparing the stereoselective biooxidation of cyclobutanones by recombinant strains expressing bacterial Baeyer-Villiger monooxygenases. Adv Synth Catal 349:1436-1444

Rudroff F, Bianchi DA, Moran-Ramallal R, Iqbal N, Dreier D, Mihovilovic MD (2016) Synthesis of tetrahydrofuran-based natural products and their carba analogs via stereoselective enzyme mediated Baeyer-Villiger oxidation. Tetrahedron 72:7212-7221

Sambrook J, Maniatis T, Fritsch EF (1989) Molecular cloning. A laboratory manual, 2nd edn. Cold Spring Harbor Laboratory Press, New York

Schmidt S, Scherkus C, Muschiol J, Menyes U, Winkler T, Hummel W, Gröger H, Liese A, Herz H-G, Bornscheuer UT (2015) An enzyme cascade synthesis of $\varepsilon$-caprolactone and its oligomers. Angew Chem Int Ed 54:2784-2787

Snajdrova R, Grogan G, Mihovilovic MD (2006) Resolution of fused bicyclic ketones by a recombinant biocatalyst expressing the Baeyer-Villiger monooxygenase gene Rv3049c from Mycobacterium tuberculosis H37Rv. Bioorg Med Chem Lett 16:4813-4817

Stewart JD, Reed KW, Zhu J, Chen G, Kayser MM (1996) A "Designer Yeast" that catalyzes the kinetic resolutions of 2-alkyl-substituted cyclohexanones by enantioselective Baeyer-Villiger oxidations. J Org Chem 61:7652-7653

Stewart JD, Reed KW, Martinez CA, Zhu J, Chen G, Kayser MM (1998) Recombinant baker's yeast as a whole-cell catalyst for asymmetric Baeyer-Villiger oxidations. J Am Chem Soc 120:3541-3548 
Surburg H, Panten J (2006) Common fragrance and flavor materials: preparation, properties and uses. Wiley, Hoboken

Szolkowy C, Eltis LD, Bruce NC, Grogan G (2009) Insights into sequence-activity relationships amongst Baeyer-Villiger monooxygenases as revealed by the intragenomic complement of enzymes from Rhodococcus jostii RHA1. ChemBioChem 10:1208-1217

Taschner MJ, Black DJ (1988) The enzymatic Baeyer-Villiger oxidation: enantioselective synthesis of lactones from mesomeric cyclohexanones. J Am Chem Soc 110:6892-6893

Torres Pazmiño DE, Dudek HM, Fraaije MW (2010) Baeyer-Villiger monooxygenases: recent advances and future challenges. Curr Opin Chem Biol $14: 138-144$ van Beek HL, Winter RT, Eastham GR, Fraaije MW (2014) Synthesis of methyl propanoate by Baeyer-Villiger monooxygenases. Chem Commun 50:13034-13036

Völker A, Kirschner A, Bornscheuer UT, Altenbuchner J (2008) Functional expression, purification, and characterization of the recombinant BaeyerVilliger monooxygenase MekA from Pseudomonas veronii MEK700. Appl Microbiol Biotechnol 77:1251-1260

Yachnin BJ, McEvoy MB, MacCuish RJ, Morley KL, Lau PC, Berghuis AM (2014) Lactone-bound structures of cyclohexanone monooxygenase provide insight into the stereochemistry of catalysis. ACS Chem Biol 9:2843-2851

\section{Submit your manuscript to a SpringerOpen ${ }^{\circ}$ journal and benefit from:}

- Convenient online submission

- Rigorous peer review

- Immediate publication on acceptance

- Open access: articles freely available online

- High visibility within the field

- Retaining the copyright to your article 